\title{
Challenges to globalisation, localisation and Sinophilia in music education: A comparative study of Hong Kong, Shanghai and Taipei
}

\author{
Wai-Chung $\mathrm{Ho}^{1}$ and Wing-Wah Law ${ }^{2}$ \\ ${ }^{1}$ Department of Music, Hong Kong Baptist University, 224 Waterloo Road, Kowloon Tong, Kowloon, \\ Hong Kong, China \\ ${ }^{2}$ Faculty of Education, The University of Hong Kong, Pokfulam Road, Hong Kong, China
}

tediwch@hkbu.edu.hk and wwlaw@hkusua.hku.hk

In the past, the music curricula of Hong Kong (HK), Mainland China and Taiwan have focused on Western music, but with the advent of music technology and the new tripartite paradigm of globalisation, localisation and Sinophilia this has begun to change. Hong Kong, Shanghai and Taipei share a common historical culture and their populations are mainly Chinese, but their recent socio-political experiences have been diverse. This paper ${ }^{1}$ aims to explore the secondary school cultures of Hong Kong, Shanghai and Taipei by examining the similarities and differences between their musical practices and the ways in which they have delineated this tripartite paradigm. Data are drawn from questionnaires completed by 5,133 students (1,750 from HK, 1,741 from Shanghai, and 1,642 from Taipei) attending grades 7 to 9 and interviews with their 46 music teachers between March and August 2004. The survey data show that students from the three communities much prefer Western classical and popular music to their respective forms of local traditional music and to traditional Chinese styles. Though most music teachers recognise the importance of teaching traditional Chinese music, local traditional music, and other world music in schools, they believe that it is difficult to teach different types of music in the classroom. This article argues that globalisation is leading to a common cosmopolitan culture of Western musical learning in school; the emergence of traditional Chinese music, local music, and socio-political movements challenge globalisation in school music education.

\section{Introduction}

The dynamics and dilemmas associated with whether school music education is a local, national, or global affair are difficult, and the answers are complex. Globalisation stands for the emergence of a world economy, a world polity, and perhaps a world culture, in short, a world society in the widest sense of the term (see Giddens, 1991, 1995, 1999; Featherstone, 1993). As Appadurai (1990, 1996) noted, increasing globalisation engenders a central tension between cultural homogenisation and cultural heterogenisation, but at the same time there are significant disjunctures between different types of global flows and sites. The notion of globalisation is enormously complex and highly contested. For Wallerstein (1974, 1989, 1990, 1998), world system globalisation proceeds from economic interests and is blind to political and cultural discrepancies. In this article, the effects of globalisation on music education are broadly referred to as the intensification of the integration of 
information technology, along with the presence of Western and other Asian popular music and other forms of world music within the school curriculum. Localisation stands for the rise of local cultures, sometimes within, sometimes transcending, state boundaries. In music education, localisation involves learning local popular and traditional music. Sinophilia (or Sinification) is the maintenance and development of the Chinese cultural heritage and Chinese traditional music in the school curricula of the three Chinese communities: Hong Kong, Shanghai and Taipei. Hong Kong and Shanghai are cities of the People's Republic of China (PRC), and Taipei is the capital city of Taiwan. While globalisation suggests global sociocultural and economic networks, localisation and Sinophilia stress sociocultural specificity, in a limited space. The globalisation, localisation and Sinophilia within music education in this study are not given conditions, but three processes - albeit unfinished ones - which move in a certain direction.

This article demonstrates that music and music education in the three Chinese societies have been experiencing various dynamics and dilemmas in today's global interactions. Music education in Hong Kong, Mainland China and Taiwan long has been influenced by both Western culture and the reproduction of traditional Chinese culture (Ho, 2003a, 2003b, 2003c, 2004a). In this decade, popular taste in HK, Mainland China and Taiwan has favoured Japanese popular culture among the Chinese youth (see Ho, 2003d; Iwabuchi, 2002; Ogawa, 2004; Taylor, 2004). The complicated interplay of the interrelated processes of globalisation and localisation lie behind the development of popular music in Chinese communities (Dujunco, 2002; Ho, 2003d, 2004b), where traditional Chinese music has for long been treated as inferior to Western classical music, at least as secondary school curricular content (Ho, 2000, 2004a). Up to the present, no comparative research has been conducted on this topic in these communities, although studies have been conducted specifically on HK (Ho, 2000; Law \& Ho, 2004; Leung, 2004), Taiwan (Ho \& Law, 2002, 2003; Lai Kou, 2001; Lee, 2002), and Mainland China (Ho \& Law, 2004; Rogers, 1989; Ma, 1989), and comparative studies on HK and Taipei (Ho, 2003a; Lau, 2003) and Taipei and Shanghai (Ho, 2004a) have attempted to explore the ever-changing play of Chinese history and politics in relation to school cultures. No direct comparison of the music education systems of Hong Kong, Taiwan and Mainland China has been found in relation to the tripartite paradigm.

This article intends to explore the musical and non-musical dimensions of the new tripartite paradigm which is affecting Mainland China, HK and Taiwan, by examining the nature and extent of the cultural and non-cultural contents of school music education and the implications behind them. We will discuss the socio-political contexts and the cultural practices of three Chinese cities, and show how the interaction between these two factors has created their respective current conditions, before introducing the study of secondary school students' perceptions of their learned musical knowledge and musical practices over a range of activities and musical styles. Our data derive from official documents, other literature and our own survey.

\section{Music education in Hong Kong, Shanghai and Taipei}

Taiwan extended compulsory education from six to nine years (i.e. grades 1-9) in the academic year of 1968, while a policy of nine-year free, compulsory education was 
launched in Hong Kong (i.e. grades 1-9) in 1978, and a compulsory education law was enacted in China in 1986, declaring the importance of universal education. Music education is included in the school curriculum as part of arts education in Mainland China and $\mathrm{HK}$, and as a component of arts and humanities education in Taiwan for their nine-year fundamental education. These three societies have attempted to strike an explicit balance between Chinese and Western traditions in their music curricula, while also integrating other forms of world music (see Curriculum Development Council, 2002b, 2003; Ministry of Education, Mainland China, 2001a, 2001b; Shanghai Municipal Education Commission, 2004; Ministry of Education, Taiwan, 1997, 2003a, 2003b;).

Since the 1997 handover of Hong Kong, music education there has been experiencing a challenge in its efforts to integrate various cultures in respect of globalisation, Sinophilia and localisation. A significant blueprint for educational reform, Learning for Life and Learning through Life, was produced (Education Commission, 2000); it trumpeted that 'The World Has Changed, So Education Be Reformed!' These changes are inter-related, fundamental shifts in the economic, technological, cultural, and social arenas, both locally and internationally. The Music Curriculum Guide (Curriculum Development Council, 2003) encourages students to cultivate the values and attitudes of 'understanding and respecting traditions as well as values of other cultures through appraising music from different cultures' (p. 15). In order to prepare students for the challenges of the twenty-first century, the five values and attitudes of 'perseverance', 'respect for others', 'responsibility', 'national identity' and 'commitment' were proposed for the short-term phase of curriculum reform from 2001-02 to 2005-06 (Curriculum Development Council, 2002a, Booklet 3A: 2). Ho (2003a) argues that the transmission of extra-musical learning through music is also essentially a response to China's particular socio-historical needs. Traditional Chinese music is highly regarded as a means to cultivate national identity through performing and appraising this music (Curriculum Development Council, 2003: 15). The HK government hopes that the national anthem and national flag will likewise help increase students' patriotism, and it has encouraged all schools to perform a flag ceremony on the national day of 1 October (the official date of the establishment of the PRC). At the same time, schools are also encouraged to emphasise local traditions through singing and appreciating Cantonese opera (Curriculum Development Council, 2003).

Shanghai lies in central-eastern China and is located at the mouth of the Yangtze River; it is regarded as China's most comprehensive commercial and industrial centre. Since the establishment of communist China in 1949, and with the guidance of Marxism-Leninism and the thought of Mao Tse-tung, education is viewed as a means to promote high moral ideals, including rules of good conduct and the civic virtues of love for the motherland, the people, labour, science and socialism. Cultivating a love for traditional Chinese music and an understanding of the various styles of the 56 ethnic groups is strongly encouraged in order to promote students' dedication to their homeland (see Ministry of Education, Mainland China, 2001a: 26-28; 2001b: 6, 8, 13; Zhu \& Liao, 2003: 40, 60-62).

The curriculum content in Shanghai is divided into one stage for grade 1-5, one for grade 6-7, one for grade 8-9, and another for senior secondary classes (grades 1012) (Shanghai Municipal Education Commission, 2004: 28). All these stages encourage the cultivation of musical sensitivity and a love of music; the development of aesthetic judgement, and the promotion of Chinese national music, as well as foreign compositions 
(see Shanghai Committee of the Reform of Curriculum and Teaching Materials [SCRCTM], 1996, 1999; Shanghai Municipal Education Commission, 2004). The current educational reform also stresses the values of the inherited culture. In particular, the development of Peking opera (a national treasure with a history of more than 200 years) and Kunqu opera (one of the oldest operatic forms in China, with a history of more than 600 years and honoured by the United Nations Educational, Scientific, and Cultural Organisation [UNESCO] as one of 19 outstanding cultural forms of expression) in both society and schools is seen as helpful for promoting Chinese traditional culture (see People's Daily News, 8 January 2005, 27 January 2005, 22 May 2005). Students also are encouraged to develop a broader sense of aesthetics through learning world music, to know about the quantity and richness of other countries' musical cultures, and to cultivate understanding, respect and love for other countries (Ministry of Education, Mainland China, 2001a: 23; 2001b: 25; Shanghai Municipal Education Commission, 2004: 35; Zhu \& Liao, 2003: 40-41). The educational reform in Mainland China intends to produce a well-rounded education that promotes creativity, and it has urged schools to teach culture, aesthetics, morality, patriotism and collectivism in the music curriculum.

Taiwan's national identity and musical cultures suffered from various stages of colonisation: Spanish and Dutch occupation, Chinese immigration, Japanese colonisation, and the Kuomintang's (KMT) rule. ${ }^{2}$ The aborigines in Taiwan were continuously oppressed and consequently had not been able to develop and refine their unique traditional cultures. After a two-decade civil war between the KMT and the Chinese Communist Party (CCP) led by Mao Tse-tung, Chiang Kai-shek was defeated and relocated his power to Taiwan in 1949. Since then, traditional Chinese culture has become the main focus of school learning. Founded in 1979, the Taipei Municipal Chinese Classical Orchestra (TMCCO) is one of Taiwan's leading promoters of various forms of Chinese classical music. After the lifting of martial law in 1987, the issue of Taiwanese identity shifted from focusing on Chinese culture to Taiwanese culture, and even toward global cultures. Previously, Taiwanese songs were considered as rough, coarse, indelicate and low-minded. Feng Feifei, a local diva in the 1980s and also known as a 'forever diva', made many Taiwanese songs into hits, greatly transforming the impression of Taiwanese music in the 1980s. When Li Deng-hui, the first Taiwan-born president, was officially elected president in 1990, he was reconfirmed in his role in Taiwan's history, to articulate a profound cultural transformation on the island. Once dying, aboriginal culture underwent a renaissance after Li's presidency. The formation of the Formosa Aboriginal Dance Troupe in the 1990s was regarded as a major contribution to the development of aboriginal culture and music. Taiwanese opera and puppetry are encouraged, to develop students' appreciation of aboriginal cultures (see Council for Cultural Affairs Executive Yuan, 2004). Though there is no political control over or inspection of different arts, very serious pressure exists from the 'politically correct' slogans of localisation and de-sinicisation (Hou et al. 2004: 33; see also the Democratic Progressive Party, 2004). The Research Institute for the Musical Heritage opened its Ethnic Music Archive, which is regarded as the first archive devoted to ethnomusicology in Taiwan and took 13 years to build, in Taipei in October 2003. Students are required to learn about and respect various cultures, and to know about and appreciate local and world history and culture (Ministry of Education, Taiwan, 2003a). Most study of music in Taipei, however, has been based on Western musical traditions (see Ho, 2003c, 2004a; Ho \& Law, 2002, 2003). 
The music education systems of the three communities are understood to provide authorised agencies for the various cultural interests of the students as well as the society. Music education is expected to prepare children as artists, and as creators of music rather than just consumers of it (Small, 1996; also see Jorgensen, 2003, 2004); and the school music classroom should bring meaningful musical experiences of diverse cultures to students so as to reproduce the multiplicity of existing relations in the wider society (Green, 2005; also see Campbell, 2002; Regelski, 2005). Similarities between the music cultures of HK, Shanghai, and Taipei, with respect to the influence of traditional Western music and the reproduction of traditional Chinese music and folk songs are produced through identical approaches to school music education. The question of how Chinese students and music teachers respond to various musical styles and musical practices in response to local, national and global paradigms of the curricula in accordance with their evolving socio-political contexts is the theme of this study.

\section{The study}

We used a questionnaire and an interview survey in secondary schools to examine students' and teachers' attitudes towards music education in relation to the triple paradigm of globalisation, localisation and Sinophilia in learning and teaching musical cultures. The main research question is examined, as well as two subsidiary ones. The main question is: How do schools respond to musical learning involved in the tripartite process in classrooms? The subsidiary questions are:

1 How do students respond to diverse musical styles, such as traditional Chinese music, traditional Western music, local popular music, Western popular music and other types of world music?

2 What dilemmas have the students encountered in the musical culture of their music curriculum?

\section{Instruments}

The data were collected from a questionnaire-survey in Chinese, which mainly investigated students' perspectives on musical styles and activities in their music learning. The survey was designed to produce a rough mapping of globalisation, Sinophilia and localisation as shown by students' attitudes towards diverse musical cultures in their school music learning. For this purpose, students were invited to complete a 15-minute multiple-choice questionnaire. The questionnaire included both closed items and four- and five-point Likert scale items that indicated students' preferences, agreements and attitudes. The subjects responded to options concerning their music learning in four broad areas: (1) general information, such as age, gender, their instrumental learning and names of learned instruments, and their attendance at concerts; (2) the persons whom students believed to have influenced their musical learning; (3) their ranking of their preferred musical activities from a choice of 12 activities, and their preferred activities in which information technology was used in their music learning; and (4) the musical styles which they preferred to be taught in lessons (from $1=$ no comment to $4=$ much interest) from a list of 11 musical types, a 
self-assessment of their knowledge about other world music (from $1=$ not known at all to $5=$ very much), students' appreciation of other music cultures (from $1=$ no appreciation to $5=$ much appreciation), the languages which they commonly used in singing other countries' songs, and musical instruments of other world cultures taught in music lessons ( $1=$ no, 2 = yes). The data were coded and analysed (to show, for example, means, standard deviations, percentages, correlation analysis and the results of chi-square testing) using the Statistical Processor for Social Science (SPSS).

In addition, semi-structured interviews with 46 music teachers (including 15 from HK, 16 from Shanghai and 15 from Taipei) were conducted; 45 out of the 46 teacher interviews were conducted face to face on an individual basis, while one of the HK teachers was interviewed by telephone. Interview questions included the following:

1 How many years of teaching experiences do you have?

2 How many music lessons do you teach in each week/cycle? Besides music lessons, what subjects are you teaching?

3 What do you regard as the most significant changes in music education during your professional career?

4 In what ways do information technologies help you teach music?

5 What are the major musical styles that you teach in music lessons?

6 How do students respond to diverse musical styles, such as traditional Chinese music, traditional Western music, local popular music, Western popular music and other types of world music?

7 How does world music feature in your teaching? Do you think it is necessary to introduce world music into the music curriculum?

Notes were taken during the course of the interviews, which were audio taped. The interview data, which were anonymous, were transcribed manually, using Excel software.

\section{Results}

\section{Participants' demographic information}

The surveys were administered from March to June 2004, while the interview surveys were conducted from May to August 2004. Among the 45 schools, 2 were for boys, 2 were for girls, and 11 were co-educational in HK; 1 for girls and 14 co-educational in Shanghai; and 15 co-educational in Taipei. The students were between the ages of 11 and 16, and were in the seventh and ninth years of their nine-year compulsory schooling. The rationale for choosing this target group was that all the students in the sample had experienced at least six years of music education in their primary studies, and they were supposed to have been exposed to Chinese and Western classical music, Chinese traditional music (sung in either Cantonese or Mandarin), and Western (sung in English) popular music, as well as Chinese folk music from mainland China and their respective local folk music. Though Chinese and Western popular music was rarely taught in school, students were probably accustomed to it outside school. 


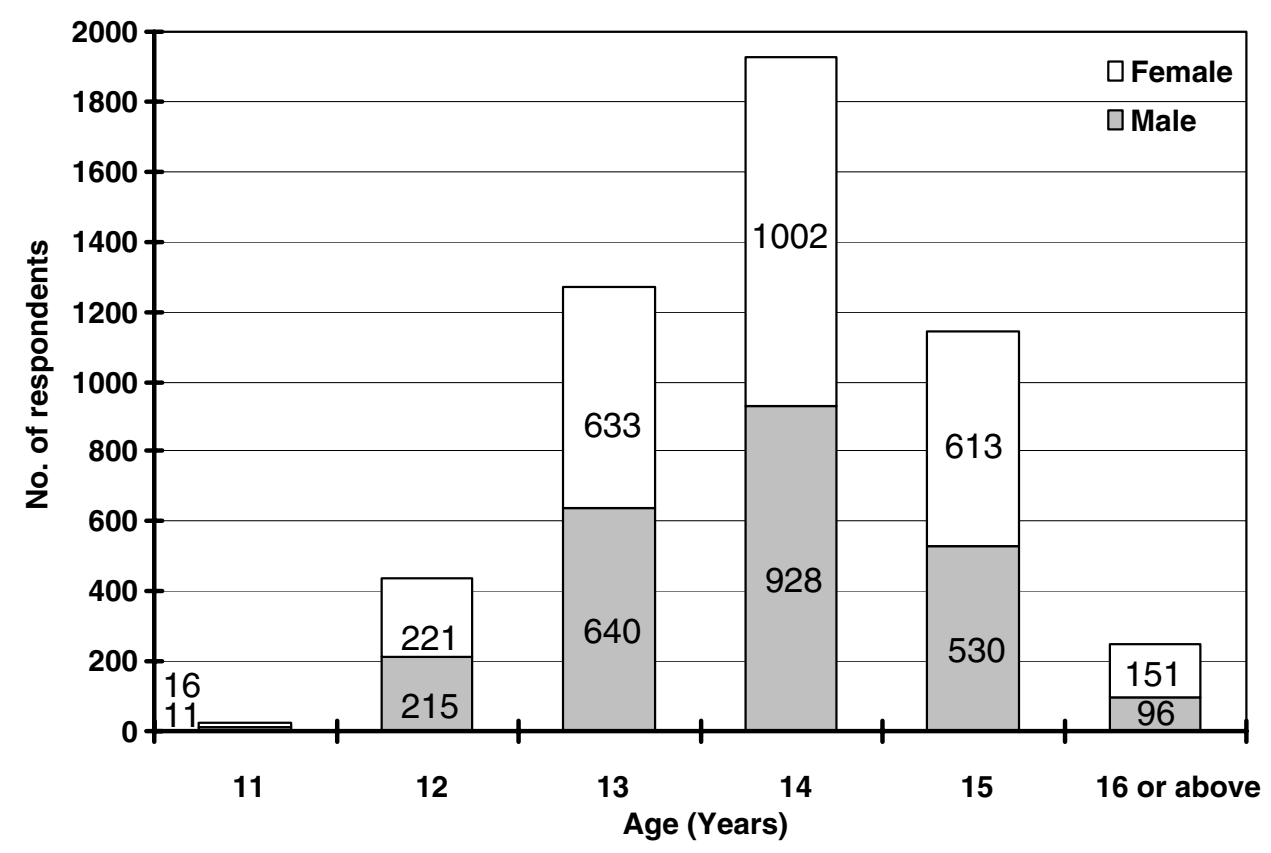

Fig. 1 Age distribution of the respondents in Hong Kong, Shanghai and Taipei

Altogether, 5,133 students, including 881 boys and 869 girls in HK, 820 boys and 921 girls in Shanghai, and 785 boys and 857 girls in Taipei, attended the junior forms (grades 7-9) of the 15 secondary schools selected in each of the three cities. Three classes from each of these 45 schools were invited to participate in the survey. Among the valid responses in the three cities, the age distribution of students was 27 students $(0.5 \%)$ who were 11 years old, $436(8.6 \%)$ who were 12 years old, 1,273 (25.2\%) who were 13 years old, 1,930 (38.2\%) who were 14 years old, 1,143 (22.6\%) who were 15 years old, and 247 $(4.9 \%)$ who were 16 years old and older (see Figure 1 ).

Students were asked about the kinds of music instruments they had learned inside and outside school. Among the HK respondents, 1,110 (65.6\%) were instrumental learners. The top five most popular instruments among HK students were piano, violin, recorder, flute and Chinese flute, with responses of 428, 135, 128, 58 and 17 respectively. Of the Shanghai students, $779(44.6 \%)$ were instrumental learners, and the top five most popular instruments among them were harmonica (263), piano (147), erhu (84), electronic piano (72) and flute (39). Finally, 1,075 (65.5\%) of the Taipei students were instrumental learners; the top five instruments were piano (479), recorder (169), flute (130), violin (76) and Chinese flute (53). Altogether, the most commonly learned instruments were piano $(1,054)$, recorder $(340)$, harmonica (321), violin (237) and flute (227).

Students were also asked how frequently they attended three types of concerts popular music, traditional Chinese and Western music, and other types of world music during a 12-month period between 2003 and 2004, depending on the date when they 
responded to the survey. The findings indicated that most students in the three cities did not attend many concerts. On the whole, popular music concerts were the most common type. Students in the three cities preferred to attend concerts of Western symphonic and piano music rather than those of Chinese classical music. Among those attending other world music concerts, jazz was the most welcomed type in all three communities.

In HK, 8 teachers had taught for 10 years or less, 7 for 11 to 17 years, and 1 for 22 years. Six Shanghai teachers had taught for 10 years or less, 5 for 11 to 20 years, and 5 for 21 to 30 years. Eight Taipei teachers had taught for 10 years or less, and 7 for 11 to 20 years. Besides music lessons, 10 of the $15 \mathrm{HK}$ teachers were required to teach other subjects. Five of them taught 12 to 15 music lessons per week/teaching cycle, 3 had 16, 5 had 20-25, and 3 had 27-30. In Shanghai, 11 out of 16 Shanghai music teachers taught only music, and their music lessons ranged between 7 and 20 per week/teaching cycle. In Taipei, 7 out of 15 needed to teach other subjects besides music, 2 of them had 10 or fewer music lessons per week/teaching cycle, and the rest had 16 to 21 .

\section{Sources of musical knowledge among students}

Students were asked to name the three most significant sources of their musical learning. Most students in the three cities listed school music teachers, the mass media, and private music tutors as their most important means for receiving musical knowledge. In HK, 700 $(41.8 \%)$ students perceived that they learned their musical knowledge chiefly from their music teachers in school, while 299 (17.9\%) students and 266 (15.9\%) students learned it from the mass media and their private music tutors respectively. In Shanghai, 718 (41.2\%) students indicated that they had learned music chiefly from their school music teachers, 369 $(21.2 \%)$ students from the mass media, and 173 (9.9\%) students from their private music tutors. The top three most influential sources among Taipei students were music teachers, with $627(38.3 \%)$ responses, the mass media with $257(15.7 \%)$, and private music tutors with $246(15.0 \%)$.

\section{Students' attitudes towards classroom activities}

Students were asked to select their customary school music activities that contributed to their music learning in the classroom or as extra-curricular activities from the following list of 12 items: (1) aural training, such as pitch and rhythm drills; (2) learning a Western musical instrument, such as piano, flute or violin; (3) learning a Chinese musical instrument, such as erhu, pipa or guzheng; (4) learning a musical instrument from another country, such as African drums; (5) music appreciation; (6) music history; (7) composition; (8) music theory, such the learning of pitch, rhythm and scales; (9) singing; (10) learning popular music, such as Mandarin, Cantonese, Japanese or Western popular songs; (11) learning Western classical music; and (12) learning Chinese classical music. The five most-favoured activities, as perceived by HK students, were learning Western musical instruments (358 responses), singing (295), learning popular music (274), aural training (202) and music appreciation (185) (see Figure 2). Among Shanghai students, the five most popular musical activities were learning popular music (401 responses), learning Western musical instruments (344), aural 


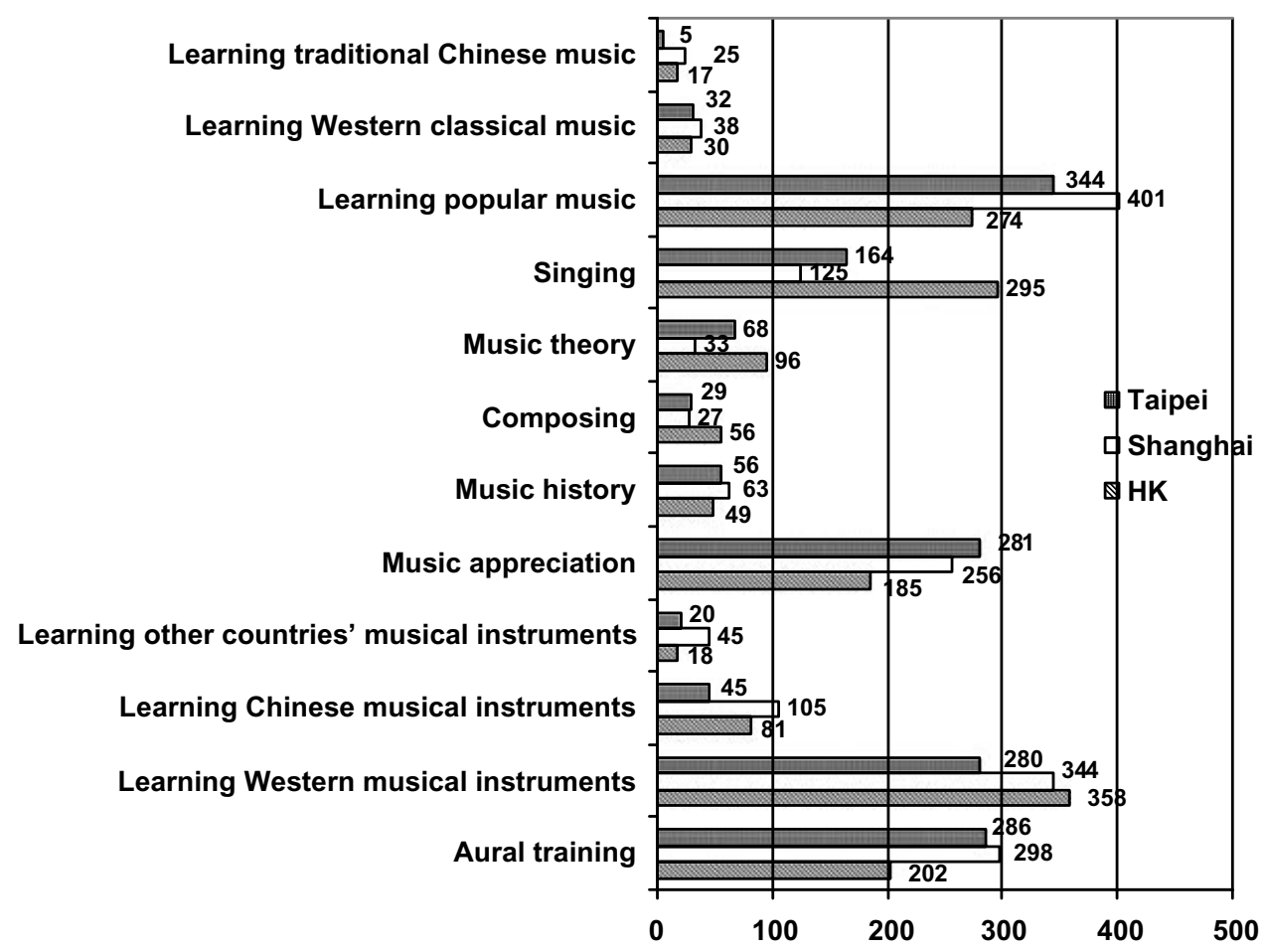

Fig. 2 Hong Kong, Shanghai and Taipei students' responses regarding their preferred musical activities in school music learning

training (298), music appreciation (256) and singing (125) (see Figure 2). Taipei students perceived the top five activities beneficial to their music learning as the study of popular music (344 responses), aural training (286), music appreciation (281), learning Western music instruments (280) and singing (164) (see Figure 2). The overall responses for the three most-preferred musical activities of students in the three cities were the learning of popular music $(1,019)$, the learning of Western musical instruments (982) and aural training (786).

Students were asked to consider whether they would like their teachers to use information technology (IT) as an aid for nine music learning activities: (1) music appreciation, (2) aural training, (3) music theory, (4) composers, (5) music history, (6) composition, (6) music instruments, (8) singing and (9) other (please specify). Music appreciation was the most popular activity for which students were interested in the use of IT in their music learning. Among HK students, the first three most popular music activities in this respect were music appreciation (649 responses), aural training (97) and music theory (91). The three most welcomed activities suggested for the use of IT among Shanghai students were music appreciation (917 responses), singing (187) and composing 
(176 entries). Among Taipei students, the most preferred activities were music appreciation, aural training, and music theory, with the responses of 950, 70 and 52 respectively.

\section{Teachers' perceptions of educational reforms and the use of information technology for classroom activities}

All music teachers in the three cities stated that changes in music education were largely due to their respective educational reforms. However, most Taipei teachers complained that there was not a standard for teaching music. They also stated that educational reforms had come too fast and that they felt slightly confused about which activities were appropriate for music lessons. Some Shanghai teachers said that they found it very difficult to design classroom activities in accordance with their students' interests, while most mentioned that the music education teaching materials were neither up-to-date nor adequate. Nine HK teachers articulated that the use of information technology and the inclusion of creativity in classroom activities were the major changes in music education, while the other six HK teachers did not perceive any important shifts in music education because they were given much freedom to design their own curricula in schools. Fifteen HK, 13 Shanghai and 15 Taipei music teachers reported using many information technology resources in music lessons, such as power-point, DVDs, VCDs and CDs. Seven HK teachers also demonstrated or taught composition software such as the 'Finale', 'Cakewalk' and 'Performer' programme. On the whole, most teachers maintained that it was a good idea to encourage students to learn music on their own, using information technology. However, many mentioned limitations to the use of information technology in music lessons, including inadequate facilities or equipment, inadequate teacher training, inadequate time in music lessons, the lack of means for monitoring students' progress, and the students' lack of technological proficiency.

\section{Students' preferences for musical styles}

The survey listed 10 musical styles and an 'other' category to be filled in using a 4-point scale $(1=$ no comment, $2=$ no interest, $3=$ some interest, $4=$ much interest $)$ that indicated what students preferred to have taught in class. HK and Shanghai shared the same preference for HK, Western and Japanese popular music. Among HK respondents, HK popular music was rated at a mean of 3.35 (see Table 1), which was followed by means of 3.09 and 2.96 for Western and Japanese popular music respectively.

The means for HK, Western and Japanese popular music among Shanghai students were, in order, 3.30, 3.24 and 3.23 (see Table 2).

Finally, Taipei students perceived Taiwan's popular music, which they rated with a mean of 3.30, as their favorite musical style to be learned in school; this was followed by Western and Japanese popular music with the respective scores of 3.18 and 3.03 (see Table 3).

Among them, the correlation between Japanese and Korean popular music was significant at $0.737(p<0.01)$, and this was the highest among all correlation values in the study. Traditional Chinese music and traditional Western music had another significant correlation at $0.6888(p<0.01)$. The data also showed that if students were interested in 
Table 1 Hong Kong students' preferences for musical styles to be taught in the classroom

\begin{tabular}{lccccc}
\hline \hline Music style & Ranking & Mean & Standard deviation & Valid total & Invalid \\
\hline Hong Kong popular music & 1 & 3.35 & 0.86 & 1,677 & 19 \\
Western popular music & 2 & 3.09 & 1.02 & 1,666 & 30 \\
Japanese popular music & 3 & 2.96 & 0.96 & 1,669 & 27 \\
Traditional Western music & 4 & 2.86 & 0.92 & 1,668 & 28 \\
Popular music from Taiwan & 5 & 2.70 & 1.45 & 1,665 & 31 \\
Korean popular music & 5 & 2.70 & 0.94 & 1,665 & 31 \\
Traditional Chinese music & 7 & 2.58 & 0.87 & 1,670 & 26 \\
Other types of music & 8 & 2.55 & 0.97 & 1,662 & 34 \\
Popular music from & 9 & 2.49 & 0.87 & 1,665 & 31 \\
$\quad$ mainland China & & & & & \\
Chinese folk music & 10 & 2.23 & 0.74 & 1,663 & 33 \\
Taiwanese folk music & 11 & 2.22 & 0.75 & 1,662 & 34 \\
\hline \hline
\end{tabular}

Table 2 Shanghai students' preferences for musical styles to be taught in the classroom

\begin{tabular}{|c|c|c|c|c|c|}
\hline Music style & Ranking & Mean & Standard deviation & Valid total & Invalid \\
\hline Hong Kong popular music & 1 & 3.30 & 0.87 & 1,656 & 129 \\
\hline Western popular music & 2 & 3.24 & 1.17 & 1,641 & 144 \\
\hline $\begin{array}{l}\text { Popular music from } \\
\text { mainland China }\end{array}$ & 3 & 3.23 & 0.88 & 1,640 & 145 \\
\hline Popular music from Taiwan & 4 & 3.21 & 0.93 & 1,634 & 151 \\
\hline Japanese popular music & 5 & 3.18 & 0.93 & 1,641 & 144 \\
\hline Korean popular music & 6 & 3.09 & 0.95 & 1,626 & 159 \\
\hline Chinese folk music & 7 & 2.81 & 0.85 & 1,608 & 177 \\
\hline Traditional Western music & 8 & 2.80 & 0.89 & 1,625 & 170 \\
\hline Traditional Chinese music & 9 & 2.68 & 0.87 & 1,625 & 160 \\
\hline Other types of music & 10 & 2.63 & 0.97 & 1,568 & 217 \\
\hline Taiwanese folk music & 11 & 2.46 & 0.87 & 1,601 & 184 \\
\hline
\end{tabular}

Chinese folk from mainland China, they would be likely to be interested in Taiwan's folk music. The statistical correlation between mainland folk and Taiwanese folk was 0.70 ( $p<$ $0.01)$.

The difference between instrumental learners and non-learners regarding music genres

The difference between instrumental learners and non-learners regarding music genre preferences was shown by the chi-square tests and the correlation coefficient. For the chisquare tests, a two-by-four (learner or non-learner by 4 degrees of interest) analysis was employed. The survey showed that instrument learners and non-learners had significantly 
Table 3 Taipei students' preferences for musical styles to be taught in the classroom

\begin{tabular}{lccccc}
\hline \hline Music style & Ranking & Mean & Standard deviation & Valid total & Invalid \\
\hline Popular music from Taiwan & 1 & 3.30 & 0.95 & 1,624 & 50 \\
Western popular music & 2 & 3.18 & 0.97 & 1,611 & 63 \\
Japanese popular music & 3 & 3.03 & 1.04 & 1,606 & 68 \\
Korean popular music & 4 & 2.73 & 1.05 & 1,589 & 85 \\
Traditional Western music & 5 & 2.71 & 1.0 & 1,596 & 78 \\
Hong Kong popular music & 6 & 2.63 & 1.01 & 1,590 & 84 \\
Other types of music & 7 & 2.49 & 1.05 & 1,572 & 102 \\
Traditional Chinese music & 8 & 2.47 & 1.06 & 1,595 & 79 \\
Popular music from & 9 & 2.47 & 1.06 & 1,595 & 79 \\
$\quad$ mainland China & & & & & \\
Taiwanese popular music & 10 & 2.43 & 0.92 & 1,581 & 93 \\
Chinese folk music & 11 & 2.13 & 0.79 & 1,581 & 93 \\
\hline \hline
\end{tabular}

different preferences $(p<0.05, d f=3$ ) in regard to their preferred music genres. Furthermore, a bivariate analysis using Pearson's correlation test was employed for determining the correlations between instrument learners and musical preference. The correlations regarding the learners' preference were significant in nine genres: traditional Chinese music (including vocal and instrumental) $(r=0.153, p<0.01)$, traditional Western music (including vocal and singing) $(r=0.031, p<0.01)$, folk in mainland China $(r=$ $0.33, p<0.1)$, folk in Taiwan $(r=0.127, p<0.01)$, Western popular music $(r=0.029, p<$ $0.01)$, Hong Kong popular music $(r=0.049, p<0.01)$, pop from Taiwan $(r=0.038, p<$ $0.01)$, pop from mainland China $(r=0.48, p<0.1)$, and Korean pop $(r=0.091, p<0.01)$.

\section{Learning and teaching various musical cultures in the classroom}

Most students in the three cities maintained that they did not know anything about world music other than that of their own community. Among the valid responses, the survey data found that $1,030(61 \%)$ of the HK, 1,143 (64.1\%) of the Shanghai and $958(57.7 \%)$ of the Taipei students perceived themselves as having little knowledge of other types of world music. Only 336 (19.9\%) of HK, 348 (19.5\%) of Shanghai and 418 (25.2\%) of Taipei students said that they had 'some knowledge'. When asked how much they liked music from other countries (from $1=$ no appreciation to $5=$ much appreciation), the mean scores of the HK, Shanghai and Taipei students were $3.52(S D=1.76), 2.59(S D=1.11)$, and $2.66(S D=1.09)$ respectively. Comparatively, $\mathrm{HK}$ students were more appreciative of world music than the other two groups.

Moreover, HK and Taipei schools paid more attention than Shanghai schools to teaching the songs of other countries in their original languages. When asked about the languages adopted for singing other countries' songs, 399 out of 1,335 (29.9\%) of the HK, 247 of 1,223 Shanghai (20.2\%) and 371 of 1,288 (28.8\%) Taipei students stated that they were taught songs in the original languages; 372 (27.9\%) and 355 (20.9\%) of the HK 
students noted that they were taught those songs in English and Cantonese respectively. Six hundred and fifty-five (54.1\%) of the Shanghai students named Mandarin and 157 $(12.8 \%)$ named English in regard to singing other countries' songs. And 358 (27.5\%) and $282(21.9 \%)$ of the Taipei students asserted that they were taught songs from other countries in Taiwanese and Mandarin respectively.

The survey data found that Chinese students in the three cities were not used to learning about other countries' musical instruments in their music lessons. Only 245 (14.5\%) of the HK students noted that they received this knowledge. Only $160(9.0 \%)$ of Shanghai and 269 (16.3\%) of Taipei students stated that they had learned about other countries' musical instruments in school music classes. For those reporting that they experienced learning the instruments of other cultures, African drumming was the most common instrument.

Most music teachers from the three cities believed that their choices of the types of music taught in lessons were greatly influenced by their own educational backgrounds. Though they agreed that other types of world music can be introduced in schools and that it was beneficial for students to learn a diversity of musical types, they gave a small proportion of time to world music in the classroom. All HK teachers in the interview survey perceived that Western classical music was the dominant type of music taught; 9 of them also taught much traditional Chinese music. Most HK teachers thought that their students did not display enthusiasm for this music; one teacher stated his only students interested in Chinese music were members of the Chinese orchestra. Eleven HK teachers expressed the view that local traditional music can be taught in lessons, but they felt limited by a lack of recordings and information about local composers. The other four HK teachers did not introduce HK music culture into their classes because they thought that it was not representative and that $\mathrm{HK}$ composers were not comparable with mainland and Taiwanese composers; one teacher admitted that she did not appreciate local HK music at all. Eight Shanghai teachers mainly taught Western classical music; six said that they taught all kinds of music, including traditional and folk Chinese music and Western classical music; and one said that she mostly taught traditional Chinese music. All the Shanghai teachers agreed that more traditional and contemporary Chinese music can be taught in lessons, and some of them mentioned that Chinese music was good. They also believed that contemporary Chinese music could help their students love the nation and become more proud of their culture. Most Taipei teachers said that they focused on all types of music in their teaching. When asked about the major type of music taught in class, four Taipei teachers said that they particularly focused on Western classical music, one on traditional Chinese music, one on popular music and two on other types of world music. Taipei teachers generally maintained that Chinese music comprised between 10 and 30\% of their music curricula. Though all Taipei teachers agreed that students could learn Taiwanese music in class, they thought their students did not display enthusiasm about it, even if the students were mostly Taiwanese.

Most teachers in the three communities found that they had difficulty in teaching different sorts of music. Ten HK teachers believed that there was not enough time to prepare materials to be taught in lessons; the other two thought it was difficult to find appropriate materials for classes, especially world music CDs. Four HK teachers said that their students generally accepted all sorts of music; one and four teachers respectively said that their students only loved musicals or popular music. Nine Shanghai teachers noted that the difficulties in teaching various musical genres included the limited time allocation 
to the music subject and the fact that their students might not be interested in the taught musical styles. All the Shanghai teachers said that their students loved popular music best, particularly popular music from HK, the mainland and Western countries. Eight Taiwanese teachers said that the difficulty of teaching different sorts of music was due to unfamiliarity with these musical types among both students and the teachers themselves, and insufficient time given to music lessons. Most teachers from the three cities commented that though most of their students preferred popular music, they would appreciate various kinds of music if teachers could find effective methods, strategies, techniques and materials for presenting them.

\section{Discussion}

This discussion is grounded in the data and focuses on the dynamics and dilemmas of globalisation, localisation and Sinophilia as they relate to three areas of music learning in schools. First, multicultural music education was not valued much in school music education. Students in the three cities perceived themselves as having little knowledge about other types of world music taught. Second, traditional Chinese music was not greatly respected in the communities' music education, while local Taiwanese music was not greatly welcomed by both students and teachers in Taipei. The education systems of HK, Taiwan and mainland China face a dilemma arising from the shared policy of combining traditional Chinese music and local folk music to effect cultural and patriotic education. Third, students in the three cities preferred to study popular music, in direct opposition to the three countries' educational systems.

The three education systems of HK, China and Taiwan have announced that global education and learning communities are thriving, as they integrate multiple cultures in their music curricula to enable students to understand how they are connected with others throughout the musical world (see Ministry of Education, Mainland China, 2001a, 2001b; Curriculum Development Council, 2003; Ministry of Education, Taiwan, 1997, 2003a, 2003b; Shanghai Municipal Education Commission, 2004). However, this study found that $1,030(61 \%)$ of the HK, 1,143 (64.1\%) of the Shanghai and $958(57.7 \%)$ of the Taipei students perceived themselves as having little knowledge about world music. Most students did not know about other countries' musical instruments and were not taught to sing other cultures' songs in their original languages. Though most teachers expressed the view that it was important to teach other types of world music, their music teaching was mainly dominated by Western classical traditions, with some traditional Chinese music. Thus the findings from this study indicate that the global cultural understanding of music actually promoted by these education systems has been narrowed to westernisation, with respect to both instrumental learning and other music practice. Most musical learning in schools has focused on Western classical music (see Ho, 2000, 2003c; Ho \& Law, 2002; Law \& Ho, 2004). Students' instrumental learning inside and outside school was mainly based on Western instruments. The piano was the most preferred learned instrument, and piano learners outnumbered other kinds of instrumental learners. Programmes of Western orchestral music and piano recitals were the public performances best received by students.

This study assumed that there is a close relationship between music teachers' preferred activities and their existing musical knowledge when they conduct their musical activities 
in classrooms. At present, effective music teachers in each of the three cities must complete a college's or university's requirements for a degree in music or music education and must demonstrate knowledge of the history of music and musical literature, music theory, solfège, harmony, composition, improvisation, orchestration and conducting. The survey data reflect that there is a need to reform music teachers' education to help in-service and pre-service music teachers understand the characteristics of ethnic and non-western music by using with them a variety of techniques in teaching music and exploring issues in school music education. Drawing from cultures inside and outside the Chinese and Western traditions, music teachers can play an important role in shaping a new musical and cultural worldview. They are the ultimate key to educational change as they develop, refine and interpret the music curriculum (Jorgensen, 2003, 2004).

At both the local and global levels, globalisation should be considered in terms of the challenges it poses to the role of government and school authorities in transmitting global cultures in school education. Music education and teacher training have passed through the digital era. More awareness is needed of how music teachers can take advantage of the media and promote the presence of the various musical traditions and world music in school. These challenges go well beyond the classroom, and confront society at large. They are addressed not only by the teachers acting alone, but by school and government officials, who need to work together. The actual practice of music and the transformation of school music education appeal to the highest aspirations of musicians, teachers and their publics (see Jorgensen, 2003, 2004; Green, 2005; Regelski, 2005).

Second, traditional Chinese music is included in schools to celebrate the cultural past of these three communities (see Ho, 2003c, 2004a; Ho \& Law, 2002). However, with economic globalisation, markets in the three Chinese cities are being flooded with Western, Japanese, and even Korean popular arts. This is what Wallerstein (1989) claimed: that the basic economic organisation of the world system is imposing a single, worldwide division of labour that unifies multiple, cultural systems into a single economic system. Chinese traditional arts, like Peking Opera, traditional Chinese folk, and Taiwanese folk, are suffering. Most students in the three Chinese communities are unfamiliar with traditional Chinese music, while their world is shrinking by the day because of popular culture's overwhelming impact. This study's findings indicate that students are less likely to learn Chinese musical instruments, traditional Chinese music and Chinese folk music than other musical forms (see Figure 2 and Tables 1-3). At present, the educational authorities of the three Chinese cities lack a long-term plan to publicise their cultural heritage among the younger generation. In this respect, the authorities can take steps to organise more cultural activities to promote music traditions' popularity. For example, the Ministry of Culture of Mainland China has ordered each of the country's seven professional Kunqu theatres to present 20 free public performances at Chinese colleges in 2005 (see People's Daily News, 8 January 2005). Regarding the issue of integrating local, global, and Chinese cultures into the school curricula, information and communication technology has impacted teaching and learning in efforts to search for new frontiers and to enhance musical knowledge related to performing, composing, and listening in music classrooms. With the aid of modern computer technology, the materials for learning traditional Chinese music can be turned into digital products and put on the internet. Thus, students will have more opportunities to explore and learn about Chinese music. However, traditional musics are not just about 
the past, and they are often still dynamic. Many contemporary composers in the three cities use the traditional style of Chinese music in terms of the harmony, instrumentation, texture, etc. Traditional musics are also able to change in response to other musical styles, with an integration of other world music elements and music technology. Students can be encouraged to understand the developments and trends in music, developing their musical competence comprehensively through listening, performing and creating activities in the school music curriculum.

Moreover, this study found that instrumental learners and non-learners had a significant difference ( $p<0.05, d f=3$ ) in their preference for particular music genres; the correlations regarding the preference of music genres were significant among traditional Chinese music, traditional mainland folk and Taiwanese folk music, and between traditional Chinese and Western classical music. We hypothesise that if more students become involved in instrumental learning, they are likely to develop an understanding of music in relation to culture and other content areas and to cultivate musical skills in performing and listening to a variety of musical genres. Children are open to listening to various genres of music at the time of their early elementary education. After that time, their interest in popular music may increase, while their preference for 'non-popular' or 'classical' music decreases. Thus traditional Chinese music can be taught at an early stage in students' education.

Third, the contemporary revolution in communication technology has had a dramatic impact in the arena of popular culture. At the same time, globalisation has increased the easy and inexpensive transmission of popular culture in Asian societies, as well as throughout the rest of the world. Chinese students consume much mass-media culture that correlates with their values and social perceptions. MTV, which originated in the USA, is now acknowledged by many as the leading global youth brand. Students' exposure to other modes of mass media, such as the Internet, CDs, VCDs, DVDs and MP3s, which has grown in both the breadth and depth of students' daily lives, enables a wide diversity of locally based popular culture to develop and reach a larger audience. Today, the governments of the three cities adopt a 'non-intervention' policy towards economic development that allows the growth of local popular music. The Chinese students all indicate a clear preference for popular music (see Tables 1-3). Most Shanghai students in this study opted for Cantonese popular songs as their most preferred musical style and music for concerts (see Table 2). The influence of Cantonese popular songs on China has increased recently due to the popularity of films and television programmes from Hong Kong. This study also found that the correlation between preferring Japanese and Korean popular music was significant at $0.737(p<0.01)$, and this was the highest among all the correlation values in the study. The export of Japanese media and culture, such as Pokémon, anime, popular music, and television dramas, is big business in Asian countries. In recent years, Korean popular culture, including television dramas, movies, fashion, and popular music, has been disseminated primarily through the mass media, enjoying a broad popularity outside Korea in such countries as the Mainland China, Hong Kong, and Taiwan (see Ho, 2004b). Influenced by popular and commercial industries outside schools, Chinese students cultivate their interest in popular music provided by the media industry, which ensures that they conform to culturally shared beliefs (Ho, 2002, 2003d, 2004a). We believe that the importance of popular music and its connection to school education lies in the role that it plays as a site for engaging the process of democratic practice. Learning both popular and folk songs 
from throughout the world is a broad-based accomplishment that students can achieve in a balanced, sequential music education programme. As a reflection of students' life experiences, music teachers should be encouraged to engage students in a deep exploration within the school curriculum of popular music's multiple dimensions.

\section{Conclusions}

The significance of this comparative study is that it explains musical learning as a reflection of the relative internationalisation and socio-political ideologies of Mainland China, HK and Taiwan, and it examines how their music curricula are restructured in accordance with available local and global awareness, information technology, and the diverse needs of students and society. This article has articulated the concepts of globalisation and its related key areas in an overall framework, and analysed how global relationships are felt in local and national contexts, as well as how they alter the construction of musical meanings in the school music education of HK, Mainland China and Taiwan. While many view globalisation as having the potential to make societies richer by bringing knowledge and information to people throughout the world, many others perceive it as a threat to traditional cultures. The distinctive tastes of the students for popular music in this sample were widely shared and definite, in contrast to the classical musical learning of their music teachers.

Music education can aim to heighten students' awareness of the need to participate actively in musical practices from different parts of the society, to be mindful of their own development, and to be not only passive consumers of the music most often encountered. Chinese music is an integral part of the school curricula of Hong Kong, China and Taiwan, and it continues to play a prominent role in the development of personal and national identity. As such, through music education, students are taught to experience music in a conscious and deliberate way. There is much work to be done to make sure that schools do not lose sight of the great musical canons, ranging from classical to folk to popular music. This is an issue for life-long learning, so that as students go through life they will experience moments of great music. Music teachers need to pay special attention to developments associated with cultural globalisation, and to the rapid migration of cultural and economic capital and electronically mediated images.

In the plurality of the social and cultural sites of practice reflected in this article, we specifically addressed questions concerning the reproduction of musical culture and identity, as they relate to contemporary educational debates. Given this range of cultural practices, how can we address the topic of locating various musical cultures and identities in the organisation of school knowledge? We suggest that pedagogical interventions that privilege classical, popular and folk music as sites of legitimate critique can open up new avenues of exploration and investigation into a radical, progressive democracy premised on the basic values of culture and equality for all humanity, with music at the local, national, and global levels being equally important. Teachers are encouraged to embody the power of knowing one's cultural roots and to widen their knowledge of different cultural contexts. This article has argued that globalisation is never antithetical to localisation and Sinophilia; rather, they are more productively seen as mutually dependent and interrelated in the dialectical socio-cultural process. The influence of globalisation, Sinophilia and 
localisation, the need for different musical skills and knowledge, and the move from teachercentred to learner-centred education have all called for redefining the role of teacher education. This paper offers some insights that call on teachers to develop the personal foundation necessary to support a professional practice that meets the needs of students in the twenty-first century. Through ongoing dialogues, music teachers, schools, government ministries and other social institutions can confirm the value of music for students and aim at expanding the diversity of the music education profession. The question of how to integrate teacher education into broader educational policies in order to promote the value of cultural differences in the school curriculum still remains to be researched.

\section{Acknowledgement}

We wish to acknowledge the generous support of the Hong Kong Research Grants Council who funded this project (HKBU 2177/03H).

\section{Notes}

1 This paper was presented to the International Association for Inter-cultural Communication Studies 2005: Modernization, Globalization and Cross-Cultural Communication, 6-8 July 2005, Taipei, Taiwan.

2 Taiwan is an island initially inhabited by nine ethnic groups of aborigines belonging to the MalayoPolynesian peoples, who are widespread among Southeast Asian islands today. The modern history of Taiwan goes back to about 400 years ago, when the first Western ship passed by the island during the age of maritime exploration in the 16th century, and Jan Huygen van Linschoten, a Dutch navigator on a Portuguese ship, exclaimed 'Ilha Formosa' (meaning 'beautiful island'). This is the origin of Taiwan's other name, Formosa. The Dutch and the Spanish colonised parts of northern and southern Taiwan. Cheng Cheng-kung, a loyalist of the fallen Ming Dynasty, expelled the Dutch in 1662 and established a government in Taiwan as a base in his attempt to restore the Ming Dynasty. The Manchus conquered Taiwan in 1683 and ruled the island until 1895. The Chinese Imperial government ceded sovereignty over Taiwan to Japan after the first Sino-Japanese war under the Treaty of Shimoneseki in 1895. Japanese development of Taiwan as a colony was extensive in areas such as education, music, business, agricultural research and development. Liberation from Japanese colonial rule came only with the defeat of Japan in 1945, and the rule of Taiwan returned to the central government of mainland China. Owing to ethnic tension, unequal treatment by the Nationalist troops and high inflation, a widespread island uprising occurred. In what is known as the February 28 Incident, between 18,000 and 28,000 native Taiwanese were brutally slaughtered

\section{References}

APPADURAI, A. (1990) 'Disjuncture and difference in the global cultural economy'. Public Culture, 2, 2, 1-24; reprinted in M. Featherstone (ed.), Global Culture: Nationalism, Globalization and Modernity, 295-310. London: Sage.

APPADURAI, A. (1996) Modernity at Large: Cultural Dimensions of the Global. Public Worlds 1. Minneapolis: University of Minnesota.

CAMPBELL, P. S. (2002) 'Music education in a time of cultural transformation'. Music Educators Journal, 89, $1,27-33$. 
COUNCIL FOR CULTURAL AFFAIRS EXECUTIVE YUAN (2004) Wenhua Baipishu (Culture white papers). Taipei: Council for Cultural Affairs.

CURRICULUM DEVELOPMENT COUNCIL, EDUCATION DEPARTMENT (2002a) Basic Education Curriculum Guide: Building on Strengths (Primary 1 - Secondary 3). Hong Kong: Government Printer.

CURRICULUM DEVELOPMENT COUNCIL, EDUCATION DEPARTMENT (2002b) Arts Education: Key Learning Area Curriculum Guide (Primary 1 - Secondary 3). Hong Kong: Government Printer.

CURRICULUM DEVELOPMENT COUNCIL, EDUCATION AND MANPOWER BUREAU (2003) Arts Education Key Learning Area: Music Curriculum Guide (Primary 1 - Secondary 3) Hong Kong: Government Printer.

DEMOCRATIC PROGRESSIVE PARTY, THE (2004) 'Ethnic diversity and national unity'. Taipei Times, 2 October, 8.

DUJUNCO, M. M. (2002) 'Hybridity and disjuncture in mainland Chinese Popular Music', in T. Craig \& R. King (Eds), Global Goes Local: Popular Culture in Asia, 25-39. Vancouver, BC: University of British Columbia Press.

EDUCATION COMMISSION (2000) Learning for Life, Learning through Life, Reform Proposals for the Education System in Hong Kong. Hong Kong: Government Printer.

FEATHERSTONE, M. (1993) 'Global and local cultures', in J. Bird, B. Curtis, T. Putnam, G. Robertson \& L. Tickner (Eds), Mapping the Futures: Local Cultures, Global Change. London: Routledge.

GIDDENS, A. (1991) Sociology. Cambridge: Polity Press [1989].

GIDDENS, A. (1995) Beyond Left and Right: the Future of Radical Polities. Cambridge: Polity Press.

GIDDENS, A. (1999) Runaway World. Cambridge: Polity Press.

GREEN, L. (2005) 'Musical meaning and social reproduction: a case for retrieving autonomy'. Educational Philosophy and Theory, 37, 1, 77-92.

HO, W. C. (2000) 'Political impact on curriculum content and musical meaning: Hong Kong secondary music education, 1949-1997'. Journal of Historical Research in Music Education, XXII, 1, 5-24.

HO, W. C. (2002) 'Musical behaviour of young Hong Kong students'. Educational Research Journal, 17, 2, 197-217.

HO, W. C. (2003a) 'Democracy, citizenship and extra-musical learning in two Chinese communities: Hong Kong and Taiwan'. Compare, 33, 2, 155-171.

$\mathrm{HO}$, W. C. (2003b) 'The sociology of China music education: westernization and social transformations, 1895-1949'. History of Education, 32, 3, 289-301.

HO, W. C. (2003c) 'Gender differences in instrumental learning, preferences for musical activities and musical genres: a comparative study on Hong Kong, Shanghai and Taipei'. Research Studies in Music Education, 20, 71-90.

HO, W. C. (2003d) 'Between globalisation and localisation: a study of Hong Kong popular music'. Popular Music, 22, 2, 145-159.

HO, W. C. (2004a) 'A comparative study of music education in Shanghai and Taipei: westernization and nationalization'. Compare, 34, 2, 231-249.

HO, W. C. (2004b) 'A cross-cultural study of preferences for popular music among Hong Kong and Thailand youths'. Journal of Intercultural Communication, 7. <http://www.immi.se/intercultural/>.

HO, W. C. \& LAW, W. W. (2002) 'Music education in Taiwan: the dynamics and dilemmas of globalization, localization and Sinophilia'. The Curriculum Journal, 13, 3, 339-360.

HO, W. C. \& LAW, W. W. (2003) 'Music education in Taiwan: the pursuit for 'local' and 'national' identity'. Journal of the Indian Musicological Society, 34, 83-96.

HO, W. C. \& LAW, W. W. (2004) 'Values, music and education in China'. Music Education Research, 6, 2, 149-167.

HOU, H. H., CHU, T. H., TANG, N. \& HSIA, C. J. (2004) 'Tensions in Taiwan'. New Left Review, 28, $19-42$ 
IWABUCHI, K. (2002) Recentering Globalization: Popular Culture and Japanese Transnationalism. Durham: Duke University Press.

JORGENSEN, E. R. (2003) Transforming Music Education. Bloomington \& Indianapolis: Indiana University Press.

JORGENSEN, E. R. (2004) 'Pax Americana and the world of music education'. Journal of Aesthetic Education, 38, 3, 1-18.

LAU, K. C. (2003) 'A Comparison of Four Sets of Music Textbooks in Hong Kong and Taipei'. Research Studies in Education, 1, 137-155.

LAI KOU, M. L. (2001) 'Development of music education in Taiwan (1895-1995)'. Journal of Historical Research in Music Education, XXII, 2, 177-190.

LAW, W. W. \& HO, W. C. (2004) 'Values education in Hong Kong school music education: A sociological critique'. British Journal of Educational Studies, 52, 1, 65-82.

LEE, A. H. C. (2002) 'The influence of Japanese music education in Taiwan during the Japanese protectorate'. Journal of Research in Music Education, XXIII, 2, 106-118.

LEUNG, C. C. (2004) 'Curriculum and culture: a model for content selection and teaching approaches in music'. British Journal of Music Education, 21, 1, 25-39.

MA, S.H.N. (1989) The Curricular Content of Elementary Music in China between 1912 and 1982. PhD Dissertation, the University of North Texas. Ann Arbor, MI: University Microfilms International.

MINISTRY OF EDUCATION, MAINLAND CHINA (2001a) Yishu Kecheng Biaozhun (Standard of Arts Curriculum). Beijing: Beijing Normal University Publisher.

MINISTRY OF EDUCATION, MAINLAND CHINA (2001b) Yinyue Kecheung Biaozhun (Standard of Music Curriculum). Beijing: Beijing Normal University Publisher.

MINISTRY OF EDUCATION, TAIWAN (1997) Zhonghua Minguo Yuanzumin Jiaoyu Baogaoshu (Report of the Republic of China aboriginal people education). Taipei: Bingyi Colorprint Publishing Company Limited.

MINISTRY OF EDUCATION, TAIWAN (2003a) Guomin Zhongxiaoxue Jiunian Yiguan Kecheng Gangyiao Zhonghe Huodong Xuexi Lingyu (Government secondary and primary school 9-year united syllabus integrated activities learning areas). Taipei: Ministry of Education.

MINISTRY OF EDUCAITON, THE REPUBLIC OF CHINA ON TAIWAN (2003b) Guomin Zhongxiaoxue Jiunian Yiguan Kecheng Gangyiao Yishu Yu Renmin Xuexi Lingyu (Government secondary and primary school 9-year united syllabus arts and humanities learning areas). Taipei: Ministry of Education.

OGAWA, M. (2004) 'Japanese popular music in Hong Kong: What does TK present?', in A. Chun, N. Rossiter \& B. Shoesmith (Eds), Refashioning Pop Music in Asia: Cosmopolitan Flows, Political Tempos, and Aesthetic Industries, 144-156. London \& New York: RoutledegeCurzon.

PEOPLE'S DAILY NEWS, Traditional Kunqu opera genre spring to life at colleges, 8 January 2005.

PEOPLE'S DAILY NEWS, China moves to reinvigorate Peking opera, (English version), 27 January 2005.

PEOPLE'S DAILY NEWS, China invests 6 million US dollars to revitalize Kunqu opera, 22 May 2005

REGELSKI, T. A. (2005) 'Music and music education: theory and praxis for 'making a difference'. Educational Philosophy \& Theory, 37, 1, 7-27.

ROGERS, K. C. (1989) 'Music education in the People's Republic of China'. Music Educators Journal, 76, 1, $43-45$.

SHANGHAI COMMITTEE OF THE REFORM OF CURRICULUM AND TEACHING MATERIALS, MAINLAND CHINA (1996) Yinyue Xueke Kecheng Biaozhun (The standardized curriculum of the music subject). Shanghai: Shanghai Educational Publisher.

SHANGHAI COMMITTEE OF THE REFORM OF CURRICULUM AND TEACHING MATERIALS, MAINLAND CHINA (1999) Mianxiang Eryi Shiji Xhongxiao Xin Kecheng Fangan He Ge Xueke Fiaoyu Gaige Xingdong Gangling: Yanjiu Biaogao (The new curriculum development for primary and secondary schools and the framework of the educational implementation of all subjects towards the twenty-first century). Shanghai: Shanghai Educational Publisher. 
SHANGHAI MUNICIPAL EDUCATION COMMISSION (2004) Shanghai Jin Zhongxia Xue Yinyue Kecheng Biaozhun (Shanghai city: standard curriculum for primary and secondary school music). Shanghai: Shanghai Educational Publisher.

SMALL, C. (1996) Music, Society, Education. Hanover, NH: University Press of New England.

TAYLOR, J. E. (2004) 'Pop music as postcolonial nostalgia in Taiwan', in A. Chun, N. Rossiter \& B. Shoesmith (Eds), Refashioning Pop Music in Asia: Cosmopolitan Flows, Political Tempos, and Aesthetic Industries, 173-182. London \& New York: RoutledegeCurzon.

WALLERSTEIN, I. (1974) The Modern World-System: Capitalist Agriculture and the Origins of the European World-Economy in the Sixteenth Century. New York: Academic Press.

WALLERSTEIN, I. (1989) The Modern World System III. San Diego: Academic Press.

WALLERSTEIN, I. (1990) 'Culture as the ideological battleground of the modern world-system'. Theory, Culture \& Society, 7, 31-55.

WALLERSTEIN, I. (1998) Utopistics: Or, Historical Choices of the Twenty-First Century. New York: The New Press.

ZHU, Z. P. \& LIAO, Y. W. (2003) Quanri zhi yiwu jiaoyu: Yinyue kecheng biaozhun jiaoshi duben (Full-day Voluntary Education: Standard of Music Curriculum Teacher's Copy). Wuhan: Hua Chung Normal University Publisher. 